\title{
Shell-and-tube evaporator model performance with different two-phase flow heat transfer correlations. Experimental analysis using R134a and R1234yf.
}

\author{
Joaquín Navarro-Esbría ${ }^{\mathrm{a}}$, Francisco Molés ${ }^{\mathrm{a}, 1}$, Bernardo Peris ${ }^{\mathrm{a}}$, Ángel Barragán-Cervera ${ }^{\mathrm{a}}$, \\ Juan Manuel Mendoza-Miranda ${ }^{\mathrm{b}}$, Adrián Mota-Babiloni ${ }^{\mathrm{a}}$, Juan Manuel Belman ${ }^{\mathrm{b}}$
}

${ }^{a}$ ISTENER Research Group. Department of Mechanical Engineering and Construction, Campus de Riu Sec s/n, University Jaume I, E12071, Castellón, Spain.

${ }^{\mathrm{b}}$ Engineering Division, Campus Irapuato-Salamanca, University of Guanajuato, Carr. Salamanca-Valle de Santiago km 3.5+1.8 km, Comunidad de Palo Blanco, C.P. 36885, Salamanca, Gto., Mexico.

\begin{abstract}
This work presents a model of a shell-and-tube evaporator using R1234yf and R134a as working fluids. The model uses the effectiveness-NTU method to predict the evaporation pressure and the refrigerant and secondary fluid temperatures at the evaporator outlet, using as inputs the geometry of the evaporator, the refrigerant mass flow rate and evaporator inlet enthalpy, and the secondary fluid volumetric flow rate and evaporator inlet temperature. The model performance is evaluated using different two-phase flow heat transfer correlations through model outputs, comparing predicted and experimental data. The output parameter with maximum deviations between the predicted and experimental data is the evaporating pressure, being the deviations in outlet temperatures less than 3\%. The evaporator model using Kandlikar's correlation obtains the highest precision and the lowest absolute mean error, with $4.87 \%$ in the evaporating pressure, $0.45 \%$ in the refrigerant outlet temperature and $0.03 \%$ in the secondary fluid outlet temperature.
\end{abstract}

Keywords: R1234yf; R134a; shell-and-tube heat exchanger; evaporator model; twophase flow heat transfer correlations.

\begin{tabular}{|llll|}
\hline \multicolumn{2}{l}{ Nomenclature } & & \\
$\dot{m}$ & mass flow rate $(\mathrm{kg} / \mathrm{s})$ & $\mathrm{k}$ & thermal conductivity $(\mathrm{W} / \mathrm{m} \mathrm{K})$ \\
$h$ & enthalpy $(\mathrm{kJ} / \mathrm{kg})$ & $\mathrm{Re}$ & Reynolds number \\
$\mathrm{T}$ & temperature $(\mathrm{K})$ & $\mathrm{Pr}$ & Prandtl number \\
$\mathrm{P}$ & pressure $(\mathrm{kPa})$ & $\mathrm{Bo}$ & boiling number \\
$\dot{V}$ & volumetric flow rate $\left(\mathrm{m}^{3} / \mathrm{h}\right)$ & $\mathrm{Co}$ & convective number \\
$c_{p}$ & specific heat capacity at constant & $\mathrm{S}$ & suppression factor \\
pressure $(\mathrm{kJ} / \mathrm{kg} \mathrm{K})$ & & \\
\hline
\end{tabular}

${ }^{1}$ Corresponding Author:

Tel: +34 964387529; fax: +34964728106.

E-mail address: franmoles.fmr@gmail.com 


\begin{tabular}{|c|c|c|c|}
\hline$C$ & heat capacity $(\mathrm{kW} / \mathrm{K})$ & $\mathrm{F}$ & Reynolds number factor \\
\hline$N T U$ & number of heat transfer units & $X$ & Martinelly parameter \\
\hline$C_{r}$ & heat capacity rate & M & molecular mass $(\mathrm{kg} / \mathrm{mol})$ \\
\hline A & heat transfer surface $\left(\mathrm{m}^{2}\right)$ & $\mathrm{q}$ & heat flux $\left(\mathrm{W} / \mathrm{m}^{2}\right)$ \\
\hline$R_{f}$ & fouling resistance $\left(\mathrm{m}^{2} \mathrm{~K} / \mathrm{W}\right)$ & $\mathrm{f}$ & friction factor \\
\hline $\begin{array}{l}U \\
\mathrm{~K})\end{array}$ & overall heat transfer coefficient $\left(\mathrm{W} / \mathrm{m}^{2}\right.$ & $\mathrm{x}$ & vapour quality \\
\hline $\mathrm{d}$ & diameter $(\mathrm{m})$ & var & variable \\
\hline Q & thermal power $(\mathrm{kW})$ & $\mathrm{P}_{\mathrm{r}}$ & reduced pressure \\
\hline \multicolumn{4}{|c|}{ Greek symbols } \\
\hline$\rho$ & density $\left(\mathrm{kg} / \mathrm{m}^{3}\right)$ & $\delta$ & error \\
\hline$\varepsilon$ & heat exchanger effectiveness & $\theta$ & standard deviation \\
\hline$\alpha$ & heat transfer coefficient $\left(\mathrm{W} / \mathrm{m}^{2} \mathrm{~K}\right)$ & $\lambda$ & error bandwidth \\
\hline$\sigma$ & surface tension $(\mathrm{N} / \mathrm{m})$ & & \\
\hline \multicolumn{4}{|c|}{ Subscripts } \\
\hline $\mathrm{r}$ & refrigerant & $\mathrm{w}$ & wall \\
\hline $\mathrm{b}$ & brine & $\mathrm{t}$ & turbulent \\
\hline out & output & tp & two-phase \\
\hline in & input & 1 & liquid \\
\hline int & intermediate & $\mathrm{v}$ & vapour \\
\hline 1 & boiling zone & $\mathrm{nb}$ & nucleate boiling \\
\hline 2 & superheating zone & $\mathrm{cb}$ & convective boiling \\
\hline $\min$ & minimum & lo & total flow as liquid \\
\hline $\max$ & maximum & sat & saturated \\
\hline $\mathrm{i}$ & inside & fg & vaporisation \\
\hline
\end{tabular}




\section{Introduction}

In recent years, chlorofluorocarbons (CFCs) and hydrochlorofluorocarbons (HCFCs) refrigerants have been replaced by hydrofluorocarbons (HFCs) refrigerants, due to their ozone depletion potential (ODP), according to the Montreal Protocol [1]. However, HFC refrigerants (such as R134a, R410A, R407C and R404A), which are entirely harmless to ozone layer, have high global warming potential (GWP) and they are considered as greenhouse gases under the Kyoto Protocol [2]. Moreover, the European Parliament established a ban for F-gases with a GWP of more than 150 for new models coming out of factories in 2011 and for all cars in 2017 [3]. As a result of all this process, efforts are made to search for refrigerant replacements for the actual fluids. One of those refrigerants to be replaced is R134a, with 100 years GWP of 1430, and extensively used in refrigeration and air conditioning, especially in mobile air conditioning (MAC). The possible refrigerants considered to replace R134a in vapour compression systems are natural refrigerants like ammonia, carbon dioxide or hydrocarbons (HC) mixtures; low GWP HFCs, highlighting R32 and R152a; and hydrofluoroolefins (HFO), specifically R1234yf, recently proposed as an alternative refrigerant for R134a in automotive air conditioning systems [4].

Focusing on R1234yf, this refrigerant has an ODP of zero [5] and its GWP is as low as $4[6,7]$. Hence, it can be accepted by the recent environmental requirements and polices. The thermophysical properties of R1234yf have been reported to be similar to those of $\mathrm{R} 134 \mathrm{a}$ [8], thereby offering an opportunity as a drop-in replacement for R134a in current mobile air conditioners. The main thermophysical properties of R1234yf are summarized in Table 1 compared with those of R134a. About security characteristics, R1234yf has low toxicity, similar to R134a, and mild flammability, significantly less than R152a [9]. Analysing the case of R1234yf would be released into the atmosphere, it is almost completely transformed to the trifluoroacetic acid (TFA), and predicted consequences of some studies of using R1234yf [10,11] show that future emissions would not cause significant increase in TFA rainwater concentrations. Several works can be found in the literature presenting theoretical and experimental studies to determine the feasibility of direct substitution (or with slight modifications) using R1234yf in vapour compression facilities working with R134a in mobile air conditioning [12], air conditioning [13] and refrigeration systems [14,15]. These works show a reduction in the coefficient of performance (COP) and the cooling capacity when using R1234yf as drop-in alternative.

Table 1. Main thermophysical properties of R1234yf and R134a.

For optimizing the system performance, both in its design and its operation, it is interesting to model the heat transfer processes that take place in vapour compression systems. Information about the two-phase heat transfer coefficient in heat exchangers (condenser and evaporator) has an important role in the performance of heat exchangers models. Park and Jung [16] reported that R1234yf and R134a have very similar nucleate boiling transfer coefficients. Del Col et al. [17] revealed that R1234yf exhibits slightly 
lower heat transfer coefficients during condensation. Focusing on the evaporation, numerous correlations have been proposed for predicting the heat transfer coefficient of two-phase flow. The evaporator model could be developed using the most appropriate two-phase flow heat transfer correlations. However, limited information is available on evaporator models with R1234yf as working fluid.

So, in the present work a shell-and-tube evaporator model with different two-phase flow heat transfer correlations is presented, experimentally analysing the performance of the model when using R1234yf and R134a. The rest of the paper is organized as follows. In Section 2, the refrigerant test facility used to obtain the experimental data is described. In Section 3, the presented model is developed and explained. In Section 4, the experimental and predicted results are presented and discussed. Finally, in Section 5, the main conclusions of the paper are summarized.

\section{Experimental setup}

The experimental tests are carried out in a monitored test bench that consists of a refrigeration vapour compression system, shown in Fig. 1, using R1234yf and R134a as working fluids.

\section{Fig. 1. Schematic diagram of the test bench.}

The main components of the vapour compression plant are a reciprocating open type compressor, driven by a variable-speed $5 \mathrm{~kW}$ electric motor (using an inverter) and using POE oil as lubricant with both refrigerants; a shell-and-tube condenser (1-2), with refrigerant flowing along the shell and water as cooling fluid inside the tubes; an electronic expansion valve; and a shell-and-tube evaporator (1-2), where the refrigerant flows inside the tubes and a brine water-propylene glycol (65/35\% by volume) is used as secondary fluid flowing along the shell.

The test bench is completed with two secondary circuits, a condensing water loop and a load simulation system, which allow varying the heat load as well as the evaporating and condensing conditions. The condenser water loop consists of a closed-type cooling system, which allows controlling the temperature of the water and its mass flow rate. The load simulation system also regulates the secondary coolant (water/propylene glycol brine) temperature through a set of immersed PID controlled electrical resistances; meanwhile its mass flow rate can be adjusted using a variable speed pump.

Focusing on the shell-and-tube evaporator, Fig. 2 presents the ONDA TE-17 evaporator and Table 2 summarizes its main characteristics. The evaporator tubes have internal micro fins used to increase the heat transfer area and to generate turbulence in the refrigerant flow. In addition, the evaporator is fully isolated by Armaflex ${ }^{\circledR}$ neoprene foam $25 \mathrm{~mm}$ thick shells, which make negligible heat losses to the environment (as it can be seen in Fig. 3, showing the cooling capacity measured at the refrigerant side and at the secondary fluid side). 
Fig. 2. ONDA TE-17 evaporator.

Fig. 3. Cooling capacity at the evaporator (comparing refrigerant side and brine side).

Table 2. Main characteristics of the ONDA TE-17 evaporator.

The thermodynamic states of the refrigerant are calculated using REFPROP [18] measuring pressure and temperature at the inlet and outlet of the evaporator, using $\mathrm{K}$ type thermocouples and piezoelectric pressure gauges. The refrigerant mass flow rate is measured by means of a coriolis effect mass flow meter and the secondary fluid flow rate is measured with electromagnetic flow meter. All the measurements are gathered with a National Instruments data acquisition system and monitored through a Personal Computer. In Table 3, a summary of the measured parameters and the sensors used in this work is presented, indicating the uncertainty associated with each measurement.

Table 3. Measured parameters and equipment uncertainty.

The experimental data consists of 100 steady-state tests obtained in a wide range of operating conditions and using R1234yf and R134a as working fluids. The ranges of all the control parameters for the evaporator are summarized in Table 4. The process of selecting a steady state consists of taking a time period of twenty minutes, with a sample period of 0.5 seconds, in which the evaporating pressure is within an interval of $\pm 2.5 \mathrm{kPa}$. Furthermore, in these tests all the temperatures are within $\pm 0.5 \mathrm{~K}$ and refrigerant mass flow rate is within $\pm 0.0005 \mathrm{~kg} / \mathrm{s}$. Then, once a steady state is achieved (with 2400 direct measurements), the data used as a steady state test are obtained selecting and averaging over a time period of five minutes (600 measurements).

Table 4. Test conditions.

\section{Model development}

The general structure of the proposed model is presented in Fig. 4, where it can be seen that the model inputs are the refrigerant flow rate, refrigerant enthalpy at the evaporator inlet and the secondary fluid input variables. Using these inputs and the geometry of the evaporator, the model predicts the evaporating pressure (neglecting pressure drops) and the refrigerant and secondary fluid temperatures at the evaporator outlet. The model computes the refrigerant properties using dynamic libraries of REFPROP [18]. Finally, the thermal analysis of heat exchange is based on the $\varepsilon$-NTU method. 
Fig. 4. Model scheme.

\subsection{Governing equations}

The evaporator behaviour is modelled considering a pure counter-current heat exchanger for simplicity [19] and dividing the heat exchanger into two zones: the evaporating zone and the superheated vapour zone, as shown in Fig. 5. The overall heat exchanger is then modelled with two energy balances: an energy balance between the two fluids (Eq. 1) and an equation with the efficiency concept (Eq. 2), where the efficiencies are estimated using Eq. 3 and Eq. 4 [20], and the NTU are evaluated as shown in Eq. 5 and Eq. 6.

Fig. 5. Temperature profile in the evaporator.

$$
\begin{aligned}
& \dot{m}_{r}\left(h_{r_{i} \text { out } \text { zone }}-h_{r_{i} \text { in,zone }}\right)-\bar{\rho}_{b} \dot{V}_{b} c_{p, b}\left(T_{b_{i} \text { in zone }}-T_{b_{i} \text { out } t_{2} \text { zone }}\right)=0 \\
& \dot{m}_{r}\left(h_{r_{i} \text { out }, \text { zone }}-h_{r_{i} \text { in,zone }}\right)-\varepsilon_{\text {zone }} C_{\min }\left(T_{b_{e} \text { in }, \text { zone }}-T_{b_{,} \text {out }, \text { zone }}\right)=0 \\
& \varepsilon_{1}=1-\exp \left(-N T U_{1}\right) \\
& \varepsilon_{2}=2\left\{1+C r_{2}+\left(1+C r_{2}{ }^{2}\right)^{1 / 2}\left[\frac{1+\exp \left(-N T U_{2}\left(1+C r_{2}{ }^{2}\right)^{1 / 2}\right)}{1-\exp \left(-N T U_{2}\left(1+C r_{2}{ }^{2}\right)^{1 / 2}\right)}\right]\right\}^{-1} \\
& N T U_{1}=\frac{U_{1} A_{1}}{C_{\min }} \\
& N T U_{2}=\frac{U_{2} A_{2}}{C_{\min }}
\end{aligned}
$$

The overall heat transfer coefficient is estimated using Eq. 7. It includes the thermal resistance associated to the fouling in the heat exchanger $\left(R_{f}=0.000086 \mathrm{~m}^{2} \mathrm{~K} / \mathrm{W}\right.$, manufacturer data for water/propylene glycol brines with less than $40 \%$ of propylene glycol),

$$
U=\left[\left(\frac{1}{\alpha_{i}}\right)\left(\frac{d_{0}}{d_{i}}\right)+R_{f}+\frac{d_{o} \ln \left(\frac{d_{0}}{d_{i}}\right)}{2 k_{t u b_{e}}}+\frac{1}{\alpha_{0}}\right]^{-1}
$$

where $\alpha_{i}$ is the refrigerant heat transfer coefficient and is different for each zone, and $\alpha_{0}$ is the heat transfer coefficient for the brine and is the same for both zones. 
To complete the characterization of the evaporator a closure equation related to the areas of heat exchange is used, as shown in Eq. 8.

$$
A_{T}=A_{1}+A_{2}
$$

The heat transfer coefficient for the brine and the refrigerant single-phase heat transfer coefficient are computed using correlations previously proven to give good results in the test bench [21]. The heat transfer coefficient for the brine, with external forced convection on an array of tubes, is computed using the Zukauskas' correlation [22], shown in Eq. 9,

$$
\alpha_{\circ}=C_{1} C_{2} R e_{D, \max }^{m} P r_{b}^{0.36}\left(\frac{P r_{b}}{P r_{b, W}}\right)^{1 / 4}\left(\frac{k_{b}}{d_{o}}\right)
$$

where coefficient $C_{1}$ depends on the number of tube lines, and coefficients $C_{2}$ and $m$ can be estimated according to the magnitude of the Reynolds number.

The refrigerant single-phase heat transfer coefficient is computed using the Gnielinski [23] correlation, presented in Eq. 10,

$$
\alpha_{i}=\frac{(f / 2)(R e-1000) P r}{1+12.7(f / 2)^{1 / 2}\left(P^{2 / 3}-1\right)}\left(\frac{k_{r}}{d_{i}}\right)
$$

where

$$
f=(0.79 \ln R e-1.64)^{-2}
$$

\subsection{Refrigerant two-phase flow heat transfer coefficients}

The two-phase flow heat transfer coefficient of the refrigerant inside the tube is one of the most important issues. Various heat transfer correlations have been proposed in the recent decades. However, most of them have not been tested with experimental data using R1234yf. So, different correlations have been selected for analyse the performance of the evaporator model using R1234yf and R134a. The correlations selected are widely accepted in the study of in-tube heat transfer previously for other refrigerants. Table 5 summarizes the correlations used for the two-phase flow heat transfer coefficient of the refrigerant.

Table 5. Refrigerant two-phase flow heat transfer correlations.

\subsection{Calculation procedure}

The flowchart of the evaporator model is presented in Fig. 6. To start the calculation the model needs some initial values for the evaporating pressure, the brine temperature and the refrigerant enthalpy at the evaporator outlet, the evaporator boiling zone area, the secondary fluid intermediate temperature between both zones of the evaporator and the wall tube temperatures (needed for the calculus of the brine side heat transfer 
correlation). These initial values are updated using the governing equations as show in the flowchart of the evaporator model. The selected initial values are calculated as indicated in Eq. 12.

Fig. 6. Flowchart of the evaporator model.

$$
\begin{aligned}
& \widehat{P}_{\text {evap }}=P_{\text {sat }}\left(T_{b, i n}\right) \\
& \hat{h}_{r, \text { out }}=h\left(\widehat{P}_{\text {evap }} \text { saturated vapour }\right) \\
& \widehat{T}_{b, \text { out }}=T_{b, \text { in }}-\Delta T_{b, \text { design }} \\
& \widehat{T}_{b, i \text { int }}=\left(T_{b, i n}+\widehat{T}_{b, \text { out }}\right) / 2 \\
& \hat{A}_{1}=0.9 A_{T} \\
& \widehat{T}_{\text {w, } 1}=\widehat{T}_{b, i n t} \\
& \widehat{T}_{\text {w, } 2}=\widehat{T}_{b, i n t}
\end{aligned}
$$

\section{Results and discussion}

In this section the performance of the evaporator model developed with different twophase flow heat transfer correlations is analysed using R1234yf and R134a as working fluids and using experimental data from the test facility presented in section 2 . The individual error, mean error, absolute mean error and standard deviation for each output variable of the model are calculated as indicated in Eq. 13, Eq. 14, Eq. 15 and Eq. 16, respectively.

$$
\begin{gathered}
\delta_{i}=\left(\frac{\text { var }_{\text {predicted }}-\operatorname{var}_{\text {experimental }}}{\text { var }}\right) \\
\bar{\delta}=\frac{1}{n} \sum_{i=1}^{n} \delta_{i} \\
|\bar{\delta}|=\frac{1}{n} \sum_{i=1}^{n}\left|\delta_{i}\right| \\
\theta=\sqrt{\frac{1}{n} \sum_{i=1}^{n}\left(\delta_{i}-\bar{\delta}\right)^{2}}
\end{gathered}
$$

In addition, the maximum deviation $\delta_{\max }$ and the percentage of points predicted within an error bandwidth of $\pm 10 \%, \lambda_{10 \%}$ is also calculated.

The comparison between the predicted results from the model and the experimental results is shown in Fig. 7, Fig. 8 and Fig. 9 for the evaporating pressure, the refrigerant temperature at the evaporator outlet and the brine temperature at the evaporator outlet, respectively. The results of the comparison are also summarized in Table 6 . 
Attending to the different variables, the evaporating pressure presents the biggest deviation between the predicted and experimental results. Kandlikar's correlation presents the best agreement with the experimental results. The absolute mean error of the model with Kandlikar's correlation is $4.87 \%$, with $93.94 \%$ of data points below $10 \%$ of error. Chen's correlation presents the largest deviations, with an absolute mean error of $10.04 \%$ and $57.58 \%$ of data points below $10 \%$ of error. The rest of correlations present similar results, with absolute mean errors between $6.05 \%$ and $7.5 \%$, and between $75.76 \%$ and $86.87 \%$ of data points below $10 \%$ of error.

Focusing on the refrigerant temperature at the evaporator outlet, Kandlikar's correlation obtains the best predictions. The absolute mean error of the model with Kandlikar's correlation is $0.45 \%$. The rest of the correlations present similar results, with absolute mean errors between $0.64 \%$ and $0.71 \%$, except for the Chen's correlation, that presents the larger deviations with an absolute mean error of $1.1 \%$ and a maximum deviation of $2.8 \%$. Regarding the brine temperature at the evaporator outlet, all the correlations present absolute mean errors below $0.1 \%$.

Fig. 7. Comparison of the evaporating pressure between the calculated and experimental results.

Fig. 8. Comparison of the refrigerant temperature at the evaporator outlet between the calculated and experimental results.

Fig. 9. Comparison of the brine temperature at the evaporator outlet between the calculated and experimental results.

Table 6. Summary of the comparison between the calculated and experimental results.

\section{Conclusions}

In the present study, a model for a shell-and-tube evaporator using R1234yf and R134a is developed. The input parameters of the model are the refrigerant mass flow rate, the secondary fluid volumetric flow, the refrigerant enthalpy at the evaporator inlet, and the secondary fluid temperature at the evaporator inlet. The model outputs are the evaporating pressure, the refrigerant enthalpy at the evaporator outlet, and the secondary fluid temperature at the evaporator outlet.

The suitability of several two-phase flow heat transfer correlations in calculating the heat transfer coefficient of the refrigerant is analysed comparing the calculated parameters with experimental results. The model with Kandlikar's correlation has the higher precision and the lowest absolute mean deviation $(4.87 \%$ for the evaporating pressure) for all the parameters. 
Hence, the developed evaporator model can be used for the performance analysis and design of a shell-and-tube evaporator working with R1234yf and R134a.

\section{References}

[1] United Nations Environment Program (UNEP), Montreal Protocol on Substances that Deplete the Ozone Layer, Final Act, United Nations, New York, USA, 1997.

[2] Kyoto Protocol, Report of the Conference of the Parties, United Nations Framework Convention on Climate Change (UNFCCC), 1997.

[3] Directive 2006/40/EC of The European Parliament and of the Council of 17 May 2006 relating to emissions from air-conditioning systems in motor vehicles and amending Council Directive 70/156/EC, Official Journal of the European Union 2006.

[4] B. Minor, M.A. Spatz, HFO-1234yf: A low GWP refrigerant for MAC, In: VDA Alternative refrigerant Winter Meeting, Saalfelden, Salzbrug, 2008.

[5] World Meteorological Organization (WMO), Scientific Assessment of Ozone Depletion: 2006, Global Ozone, Research and Monitoring Project - Report 50, Geneva, Switzerland, 2007.

[6] V.C. Papadimitriou, R.K. Talukdar, R.W. Portmann, A.R. Ravishankara, J.B. Burkholder, $\mathrm{CF} 3 \mathrm{CF}=\mathrm{CH} 2$ and $(\mathrm{Z})-\mathrm{CF} 3 \mathrm{CF}=\mathrm{CHF}$ : Temperature dependent $\mathrm{OH}$ rate coefficients and global warming potentials, Physical Chemistry and Chemical Physics 10 (2008), $808-820$.

[7] O.J. Nielsen, M.S. Javadi, A. Sulbak, M.D. Hurley, T.J. Wallington, R. Singh, Atmospheric chemistry of $\mathrm{CF} 3 \mathrm{CF}=\mathrm{CH} 2$ : Kinetics and mechanisms of gas-phase reactions with $\mathrm{Cl}$ atoms, $\mathrm{OH}$ radicals, and O3. Chemical Physics Letters 439 (2007), 18 -22 .

[8] R. Akasaka, K. Tanaka, Y. Higashi, Thermodynamic property modelling for 2,3,3,3tetrafluoropropene (HFO-1234yf), International Journal of Refrigeration 33 (2010), 52 60 .

[9] M. Koban, HFO-1234yf Low GWP Refrigerant LCCP Analysis, SAE Technical Paper 2009-01-0179, doi: 10.4271/2009-01-0179, 2009.

[10] D.J. Luecken, R.L. Waterland, S. Papasavva, K.N. Taddonio, W.T. Hutzell, J.P. Rugh, S.O. Andersen, Ozone and TFA Impacts in North America from Degradation of 2,3,3,3-Tetrafluoropropene (HFO-1234yf), A Potential Greenhouse Gas Replacement, Environmental Science Technology 44 (2010), 343 - 348.

[11] S. Henne, D.E. Shallcross, S. Reimann, P. Xiao, D. Brunner, S. O'Doherty, B. Buchmann, Future Emissions and Atmospheric Fate of HFC-1234yf from Mobile Air Conditioners in Europe, Environmental Science Technology 46 (2012), 1650 - 1658. 
[12] Y. Lee, D. Jung, A brief performance comparison of R1234yf and R134a in a bench tester for automobile applications, Applied Thermal Engineering 35 (2012), 240 -242 .

[13] C. Zilio, J.S. Brown, G. Schiochet, A. Cavallini, The refrigerant R1234yf in air conditioning systems, Energy 36 (2011), 6110 - 6120.

[14] J. Navarro-Esbrí, J.M. Mendoza-Miranda, A. Mota-Babiloni, A. Barragán-Cervera, J.M. Belman-Flores, Experimental analysis of R1234yf as a drop-in replacement for $\mathrm{R} 134 \mathrm{a}$ in a vapour compression system, International Journal of Refrigeration 36 (2012), $870-880$.

[15] J. Navarro-Esbrí, F. Molés, A. Barragán-Cervera, Experimental analysis of the internal heat exchanger influence on a vapour compression system performance working with R1234yf as a drop-in replacement for R134a, Applied Thermal Engineering (2013), doi: 10.1016/j.applthermaleng.2013.05.028.

[16] K.J. Park, D. Jung, Nucleate boiling heat transfer coefficients of R1234yf on plain and low fin surfaces, International Journal of Refrigeration 33 (2010), 553 - 557.

[17] D. Del Col, D. Torresin, A. Cavallini, Heat transfer and pressure drop during condensation of the low GWP refrigerant R1234yf, International Journal of Refrigeration 33 (2010), 1307 - 1318.

[18] E.W. Lemmon, M.L. Huber, M.O. McLinden, REFPROP, NIST Standard Reference Database 23, v.8, National Institute of Standards, Gaithersburg, MD, USA, 2007.

[19] J.M. Belman, J. Navarro-Esbrí, D. Ginestar, V. Milian, Steady-state model of a variable speed vapor compression system using R134a as working fluid, International Journal of Energy Research 34 (2010), 933 - 945.

[20] Frank P. Incropera, David P. DeWitt, Fundamentos de transferencia de calor $\left(4^{\mathrm{a}}\right.$ edn), Prentice Hall: México, 1999.

[21] J. Navarro-Esbrí, D. Ginestar, J.M. Belman, V. Milián, G. Verdú, Application of a lumped model for predicting energy performance of a variable-speed vapour compression system, Applied Thermal Engineering 30 (2010), 286 - 294.

[22] A. Zukauskas, Heat transfer from tubes in cross flow, in: J.P. Hartnett, T.F. Irvine (Eds.), Advances in Heat Transfer, vol. 8, Academic Press, New York, 1972.

[23] V. Gnielinski, New equations for heat and mass transfer in turbulent pipe and channel flow, International Chemical Engineering 16 (1976), 359 - 368.

[24] J.C. Chen, A correlation for boiling heat transfer to saturated fluid in convective flow, ASME, 1 - 11, 1963, Paper, 63-HT-34.

[25] M.M. Shah, Chart correlation for saturated boiling heat transfer: equations and further study, ASHRAE Trans. 2673, 1982, 185 - 196. 
[26] S.G. Kandlikar, A general correlation for saturated two-phase flow boiling heat transfer inside horizontal and vertical tubes, Journal of Heat Transfer 112 (1990), 219 228.

[27] K.E. Gungor, H.S. Winterton, A general correlation for flow boiling in tubes and annuli, International Journal of Heat and Mass Transfer 29 (1986), 351 - 358.

[28] Z. Liu, H.S. Winterton, A general correlation for saturated and subcooled flow boiling in tubes and annuli, based on a nucleate pool boiling equation, International Journal of Heat and Mass Transfer 34 (1991), 2759 - 2766.

[29] J. Panek, Evaporation heat transfer and pressure drop in ozone-safe refrigerants and refrigerant-oil mixtures, $\mathrm{PhD}$ Thesis in University of Illinois at Urbana-Champaign, USA, 1992. 


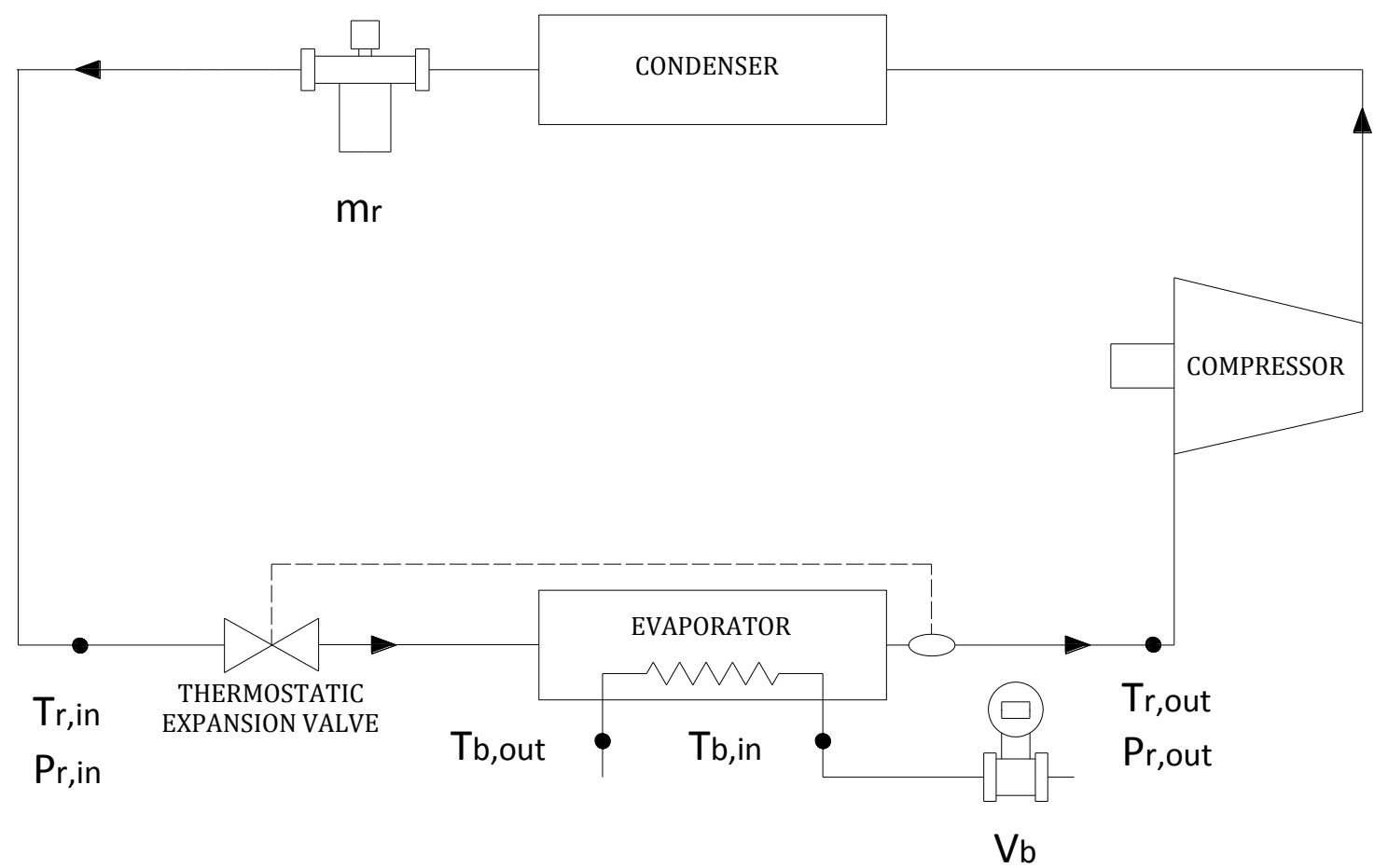

Fig. 1. Schematic diagram of the test bench. 

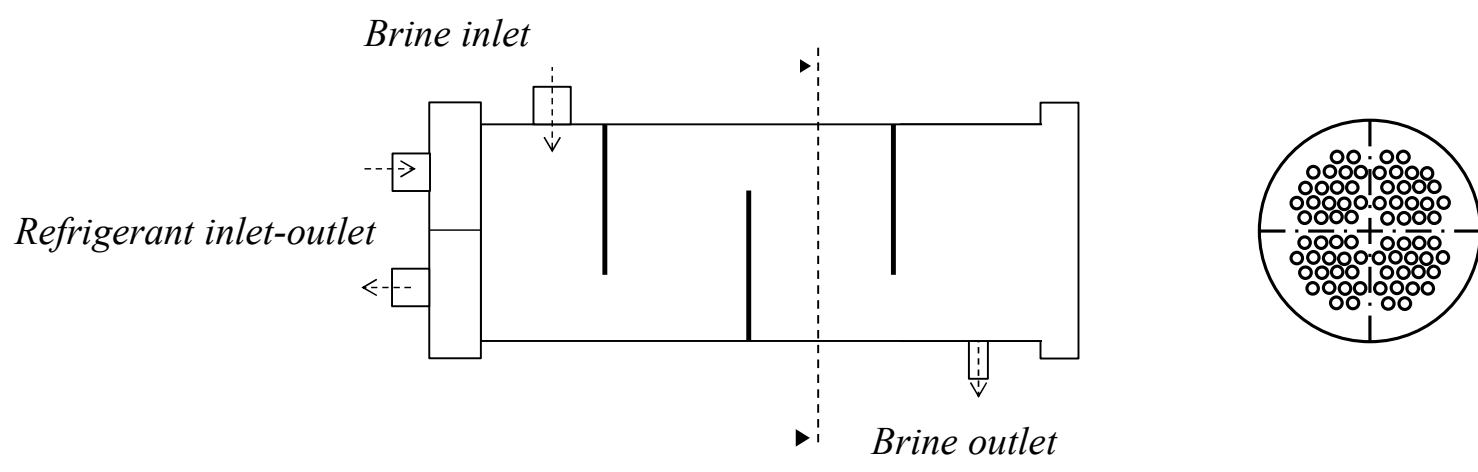

Fig. 2. ONDA TE-17 evaporator. 


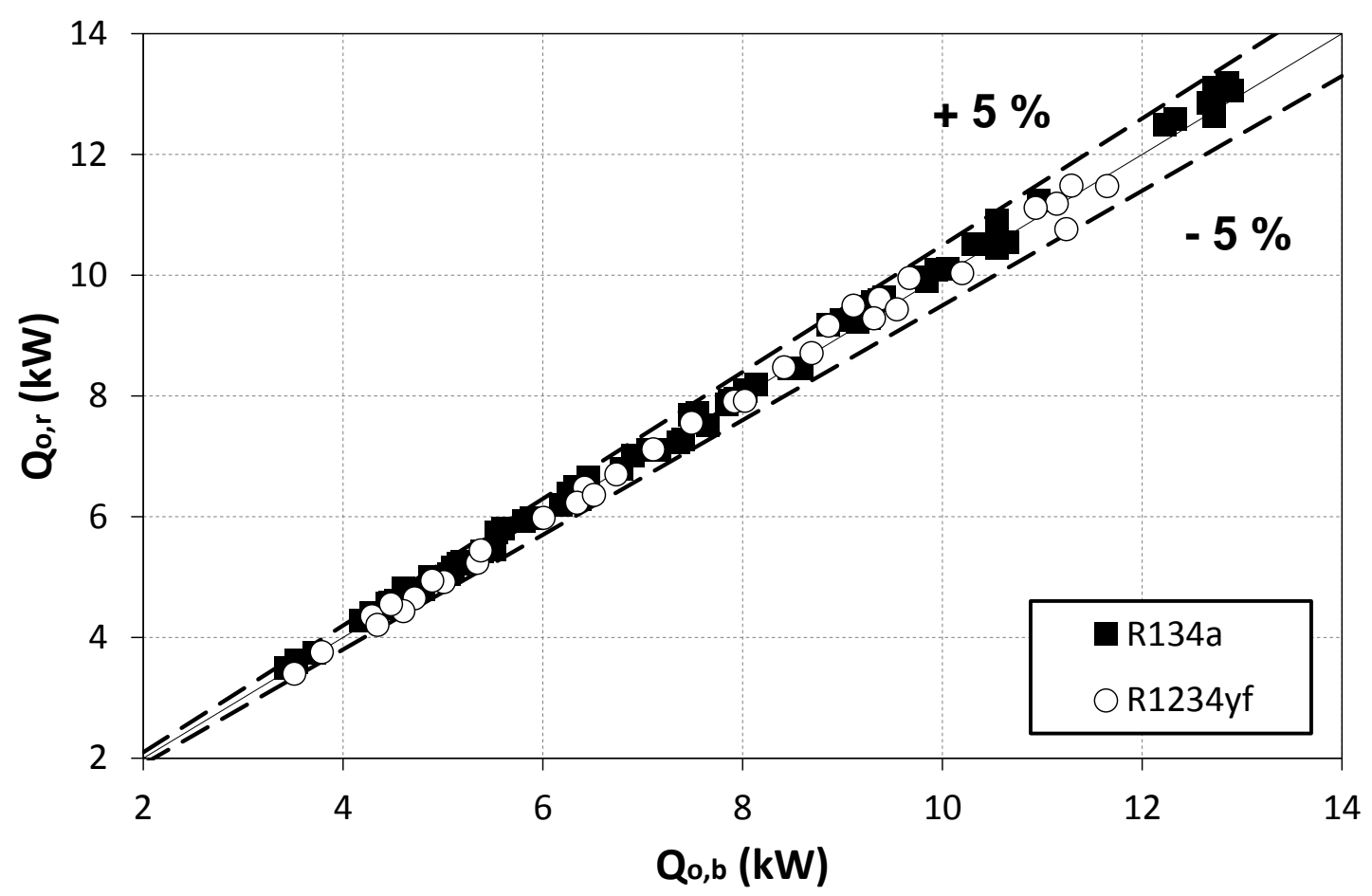

Fig. 3. Energy balance in the evaporator. 


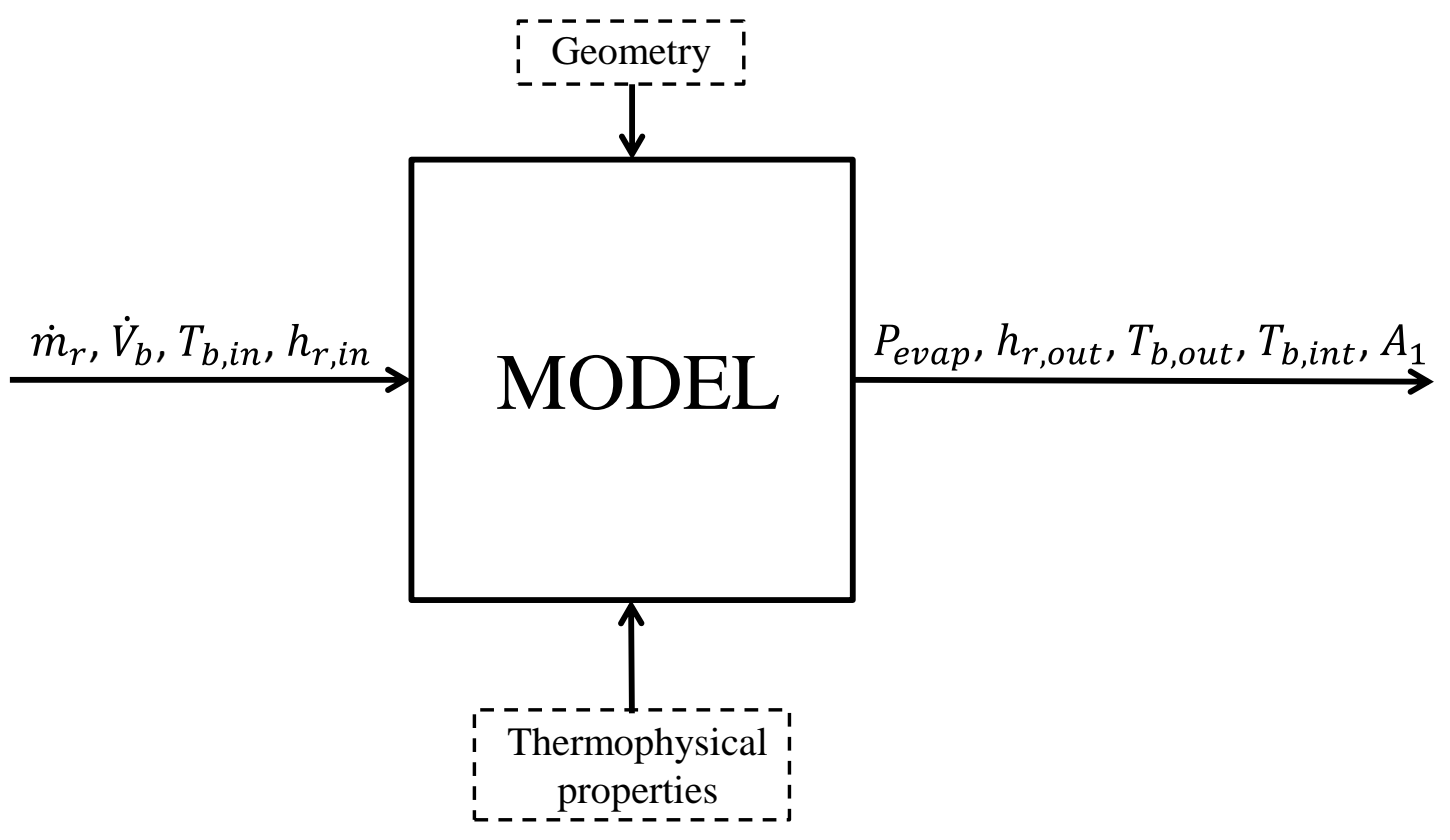

Fig. 4. Model scheme. 


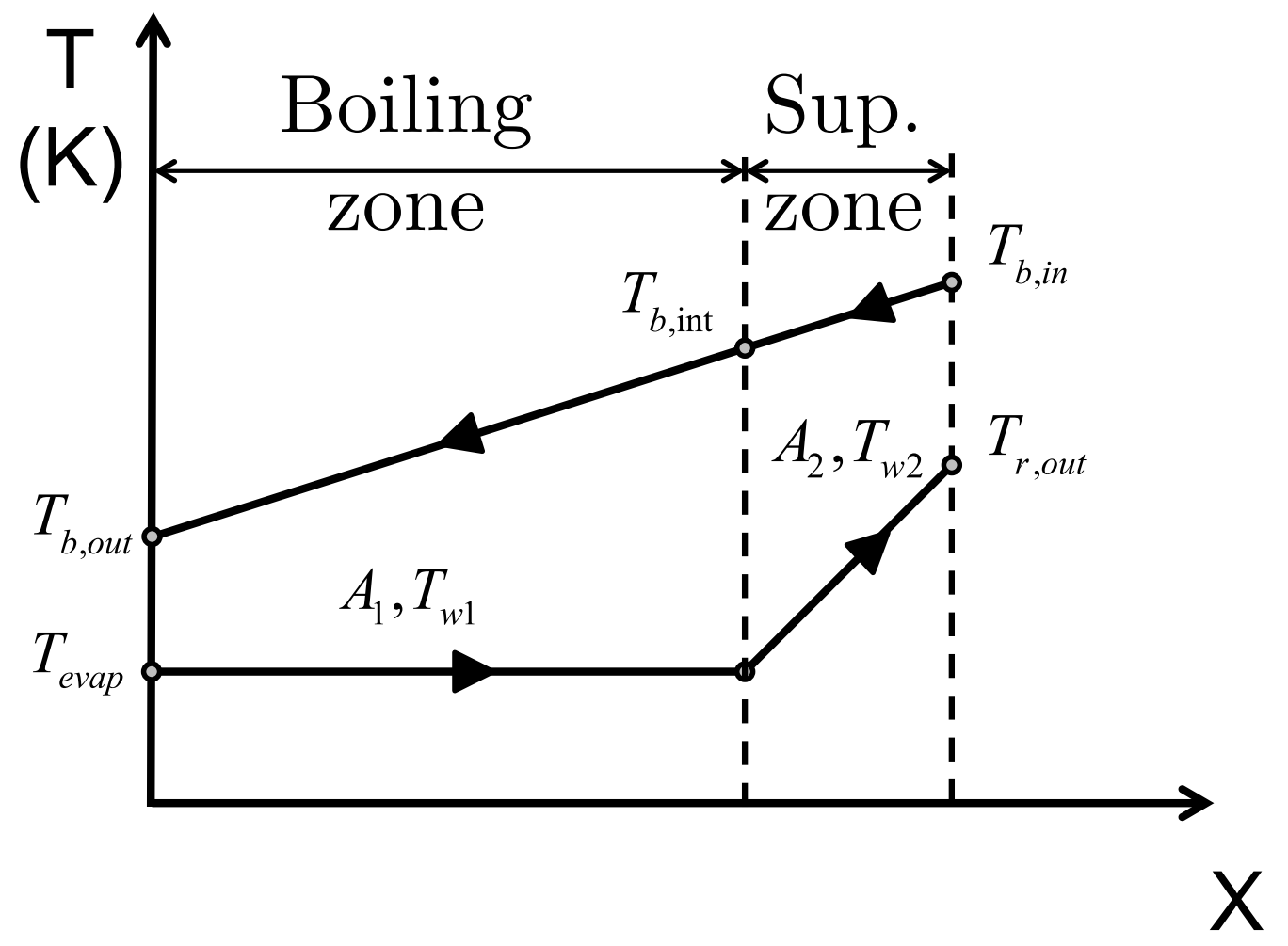

Fig. 5. Temperature profile in the evaporator. 


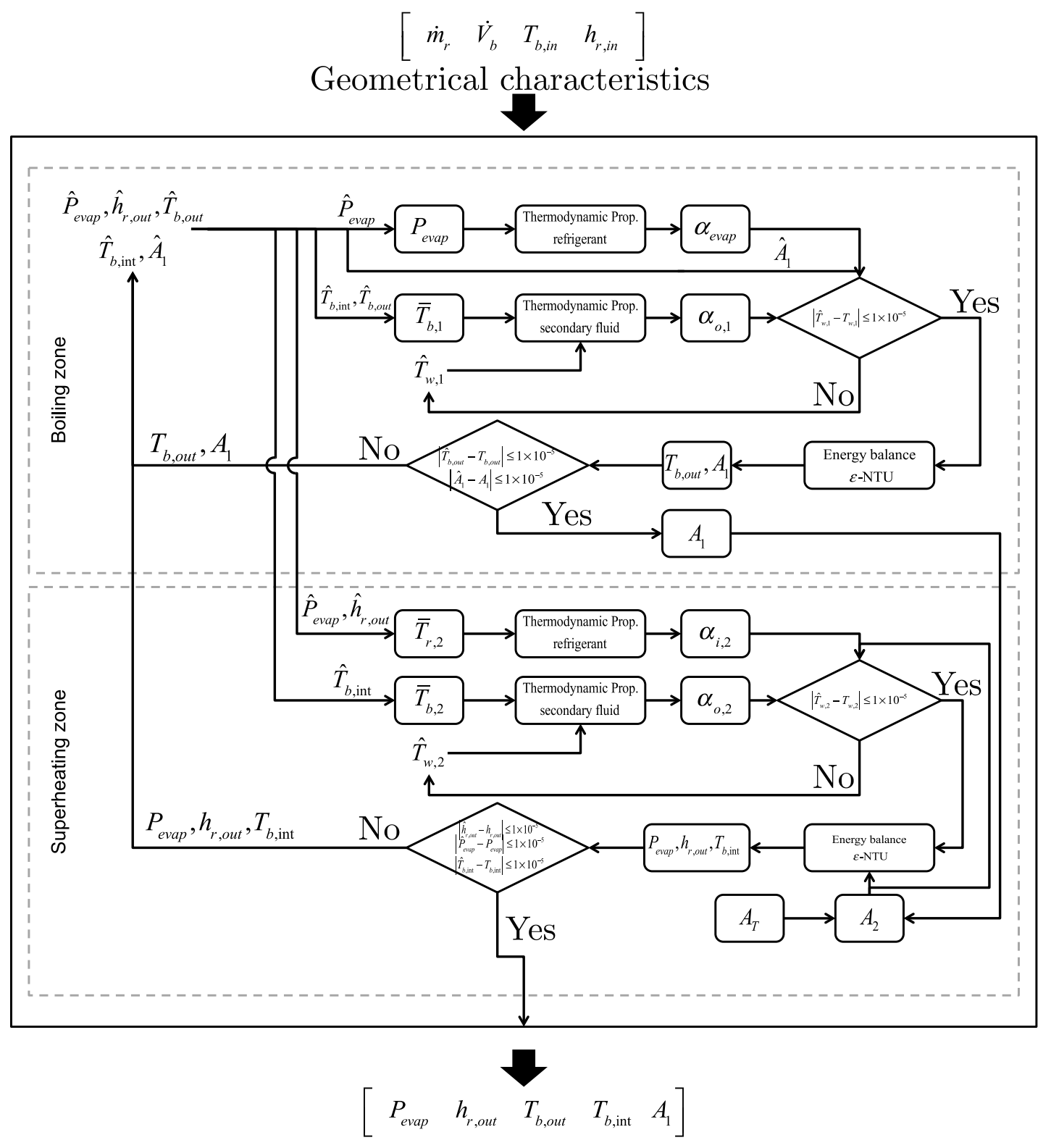

Fig. 6. Flowchart of the evaporator model. 


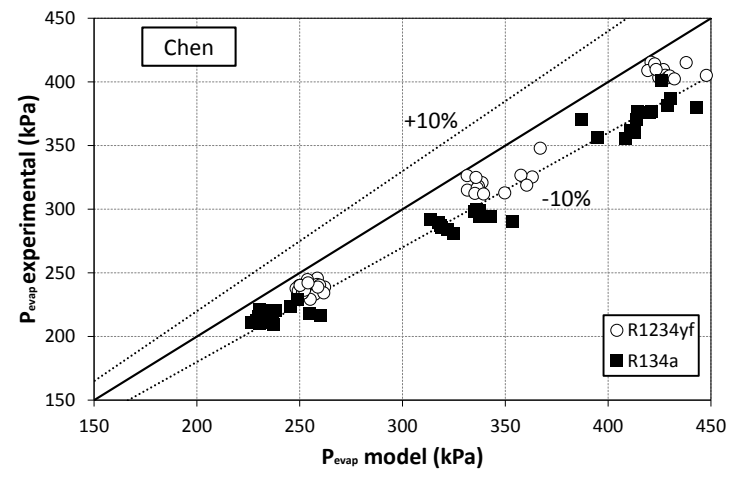

(a)

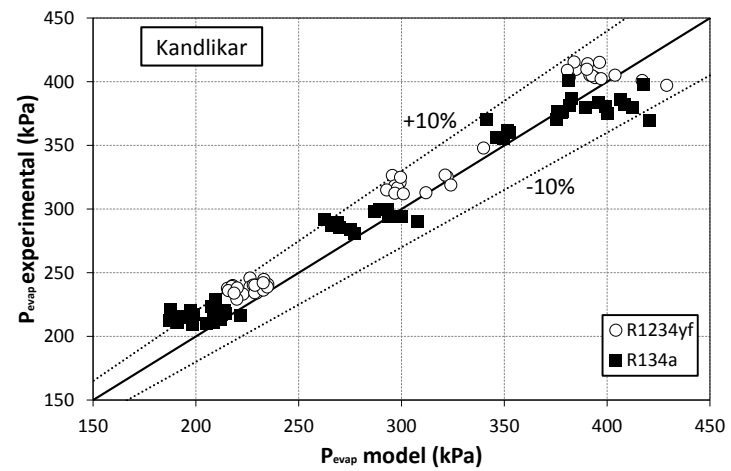

(c)

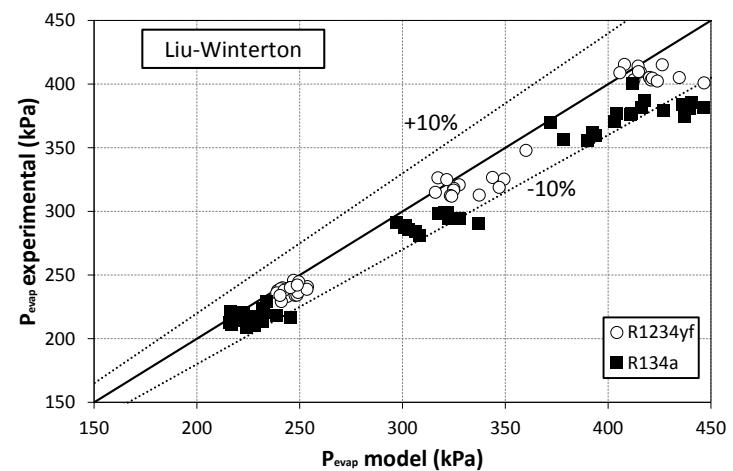

(e)

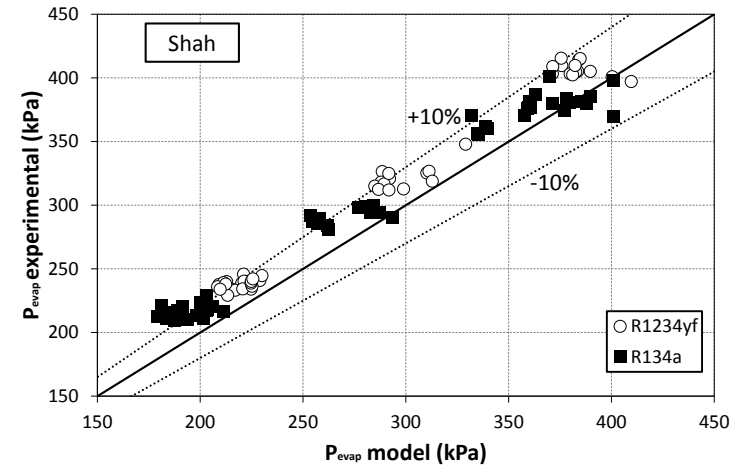

(b)

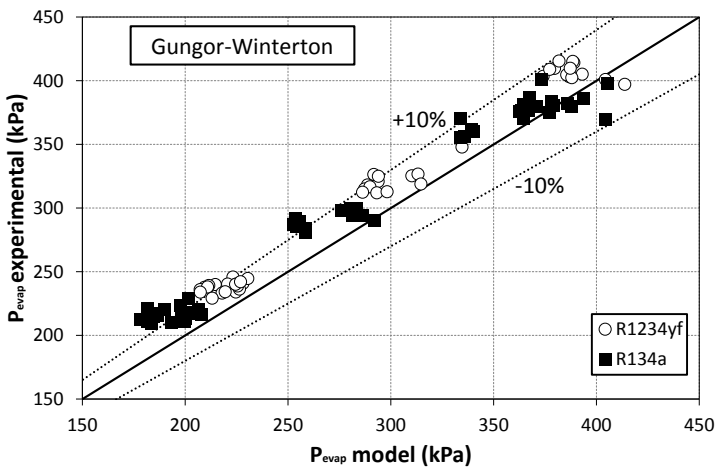

(d)

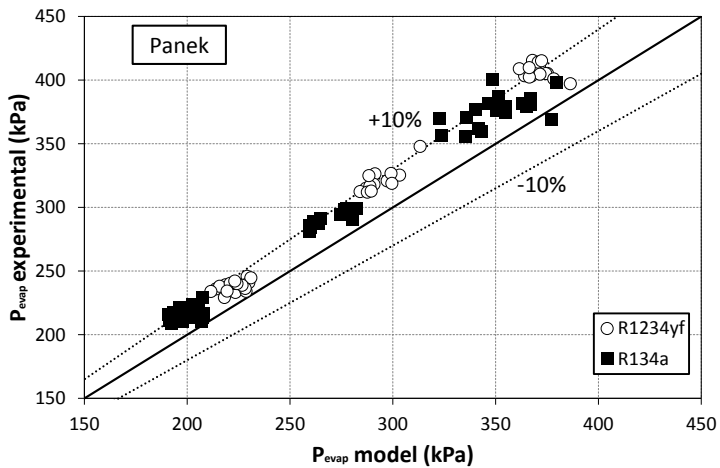

(f)

Fig. 7. Comparison of the evaporating pressure between the calculated and experimental results. 


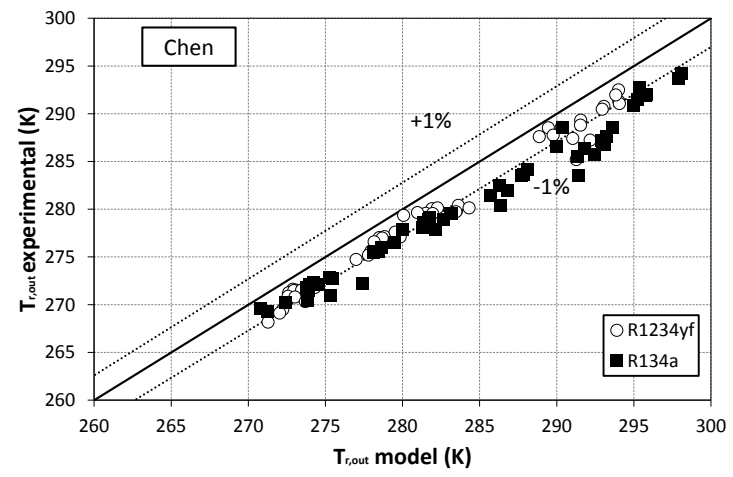

(a)

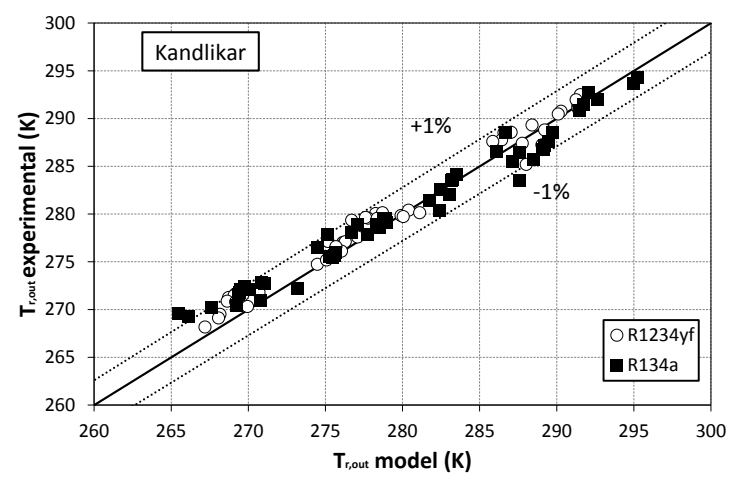

(c)

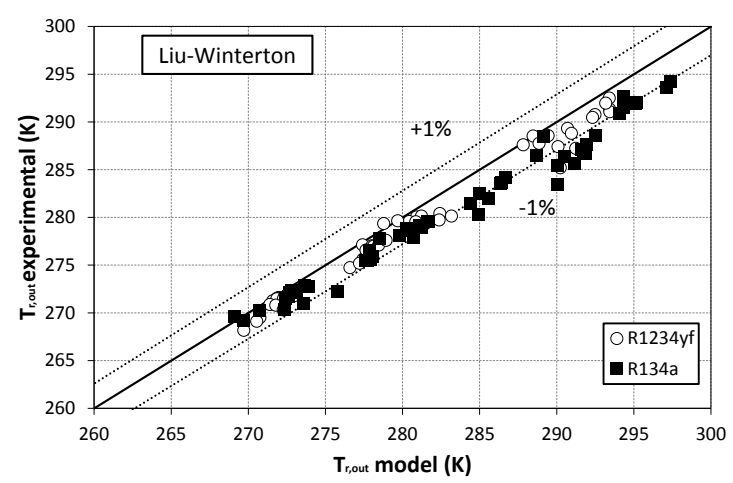

(e)

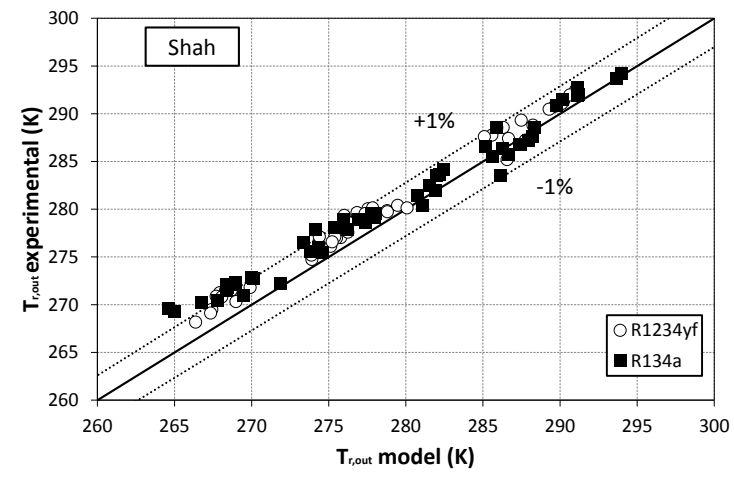

(b)

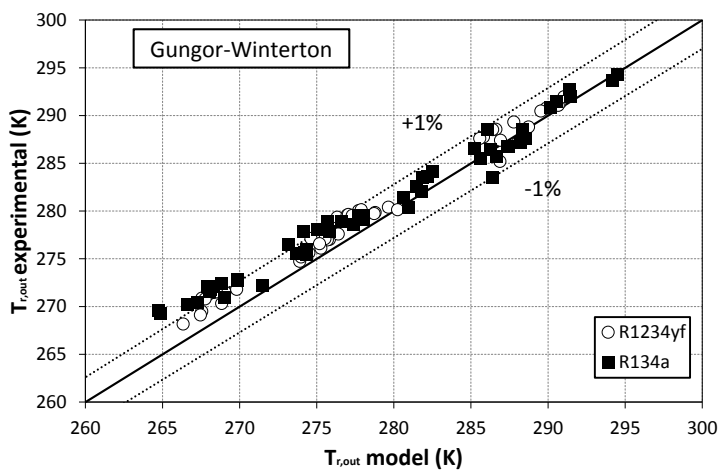

(d)

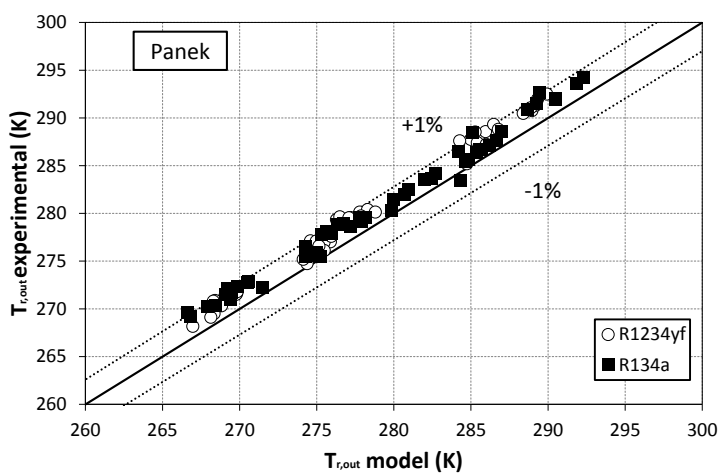

(f)

Fig. 8. Comparison of the refrigerant temperature at the evaporator outlet between the calculated and experimental results. 


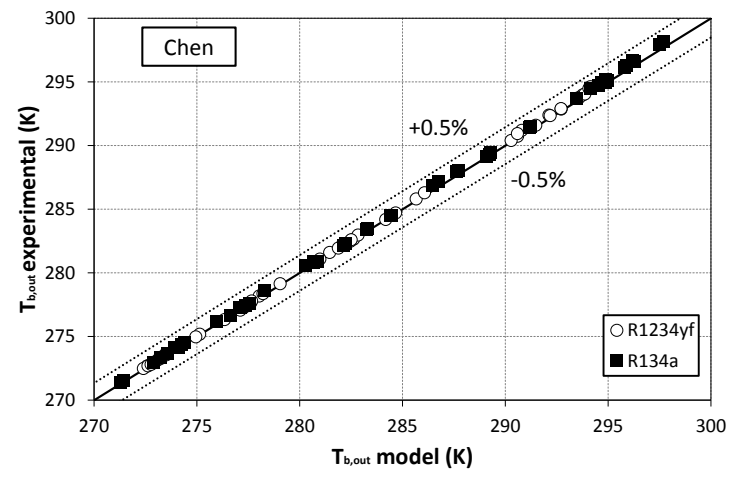

(a)

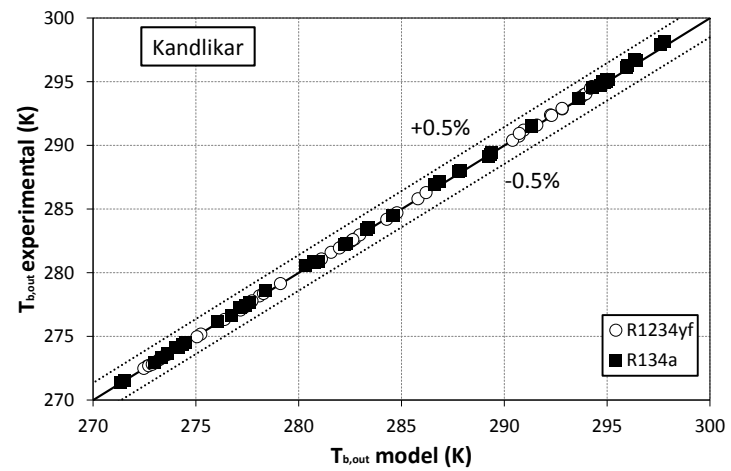

(c)

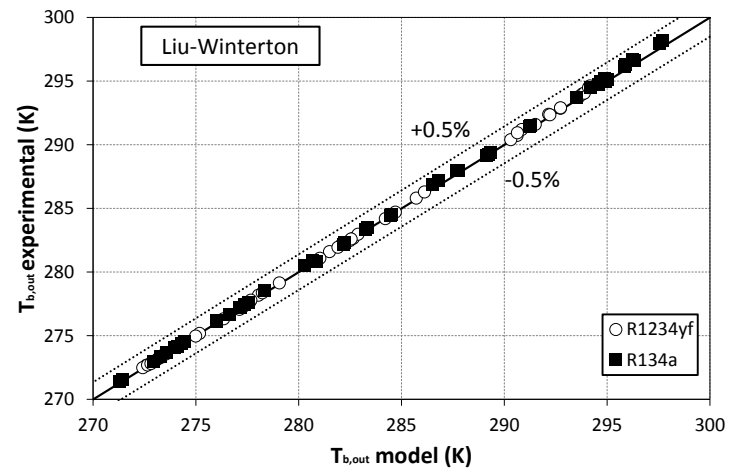

(e)

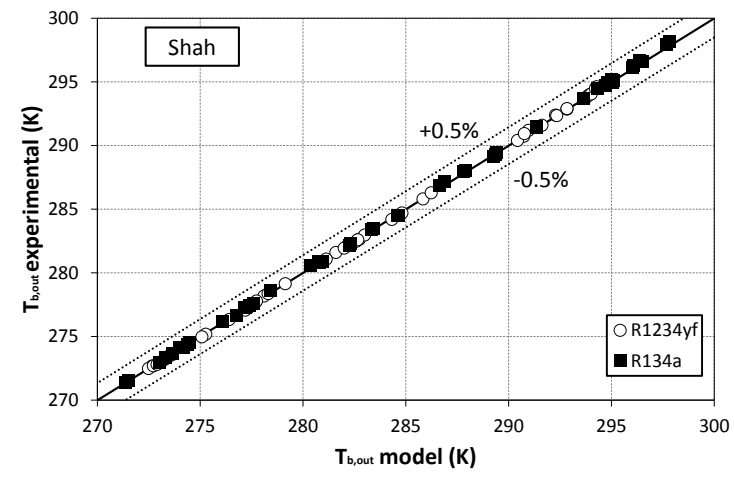

(b)

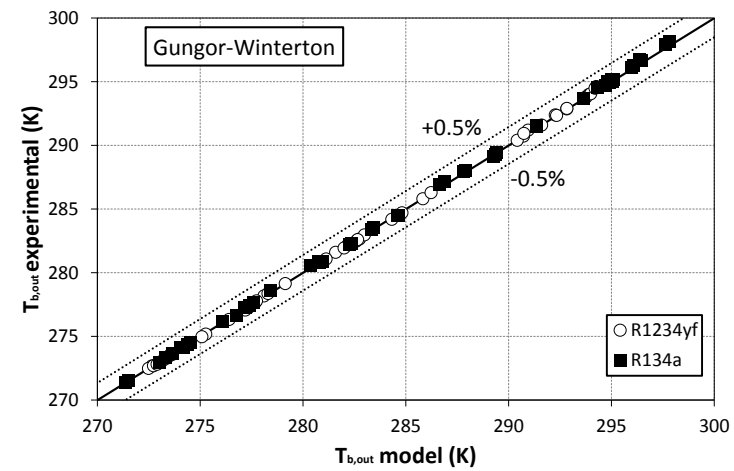

(d)

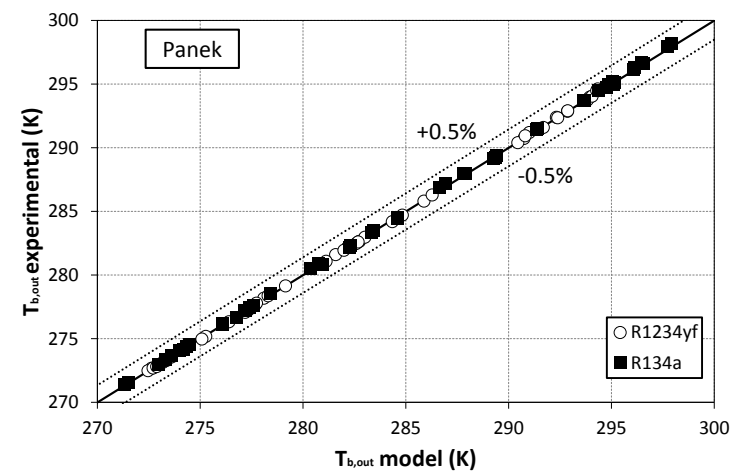

(f)

Fig. 9. Comparison of the brine temperature at the evaporator outlet between the calculated and experimental results. 


\section{FIGURE CAPTIONS}

Fig. 1. Schematic diagram of the test bench.

Fig. 2. ONDA TE-17 evaporator.

Fig. 3. Energy balance in the evaporator.

Fig. 4. Model scheme.

Fig. 5. Temperature profile in the evaporator.

Fig. 6. Flowchart of the evaporator model.

Fig. 7. Comparison of the evaporating pressure between the calculated and experimental results.

Fig. 8. Comparison of the refrigerant temperature at the evaporator outlet between the calculated and experimental results.

Fig. 9. Comparison of the brine temperature at the evaporator outlet between the calculated and experimental results. 
Table 1. Main thermophysical properties of R1234yf and R134a.

\begin{tabular}{ccc}
\hline Thermophysical property & R1234yf & R134a \\
\hline Chemical formula & $\mathrm{CF}_{3} \mathrm{CF}=\mathrm{CH}_{2}$ & $\mathrm{C}_{2} \mathrm{H}_{2} \mathrm{~F}_{4}$ \\
Boiling point $(\mathrm{K})$ & 244.15 & 247.15 \\
Critical point $(\mathrm{K})$ & 368.15 & 375.15 \\
Liquid density at 298.15 K $\left(\mathrm{kg} \mathrm{m}^{-3}\right)$ & 1094 & 1207 \\
Vapor density at 298.15 $\mathrm{K}\left(\mathrm{kg} \mathrm{m}^{-3}\right)$ & 37.6 & 32.4 \\
ODP & 0 & 0 \\
GWP & 4 & 1430 \\
\hline
\end{tabular}


Table 2. Main characteristics of the ONDA TE-17 evaporator.

$\begin{array}{lr}\text { Number of tube passes } & 2 \\ \text { Bundle tube count for pass } & 38 \\ \text { Number of baffles } & 3 \\ \text { Tube inside diameter (m) } & 0.00822 \\ \text { Tube outside diameter (m) } & 0.00952 \\ \text { Shell inside diameter (m) } & 0.131 \\ \text { Tube length (m) } & 0.01142 \\ \text { Centre distance of tubes (m) } & 0.0019 \\ \text { Distance of tubes (m) }\end{array}$


Table 3. Measured parameters and equipment uncertainty.

\begin{tabular}{ccc}
\hline Measured parameters & Sensor & Uncertainty \\
\hline Temperatures & K-type thermocouples & $\pm 0.3 \mathrm{~K}$ \\
Pressures & Piezoelectric pressure transducers & $\pm 1 \mathrm{kPa}$ \\
Mass flow rate & Coriolis mass flow meter & $\pm 0.22 \%$ \\
Compressor power consumption & Digital wattmeter & $\pm 0.15 \%$ \\
Compressor rotation speed & Capacitive sensor & $\pm 1 \%$ \\
Pressure drops in the IHX & Differential pressure transducers & $\pm 0.01 \mathrm{kPa}$ \\
\hline
\end{tabular}


Table 4. Test conditions.

\begin{tabular}{lr}
\hline Control parameters & Range values \\
\hline Evaporating pressure $(\mathrm{kPa})$ & $215.99-413.89$ \\
Refrigerant mass flow rate $\left(\mathrm{g} \mathrm{s}^{-1}\right)$ & $26.4-97.73$ \\
Refrigerant temperature at evaporator inlet $(\mathrm{K})$ & $266.41-284.57$ \\
Refrigerant temperature at evaporator outlet $(\mathrm{K})$ & $266.96-293.13$ \\
Secondary fluid volumetric flow rate $\left(\mathrm{m}^{3} \mathrm{~h}^{-1}\right)$ & $1.1439-1.2429$ \\
Secondary fluid inlet temperature $(\mathrm{K})$ & $290.75-327.83$ \\
Secondary fluid outlet temperature $(\mathrm{K})$ & $297.31-329.49$ \\
\hline
\end{tabular}


Table 5. Refrigerant two-phase flow heat transfer correlations.

Authors Correlation

Chen [24]

$$
\alpha_{t p}=F \alpha_{l}+S \alpha_{n b}
$$

$$
\begin{aligned}
& F=\left\{\begin{array}{cl}
1 & \frac{1}{X_{t t}} \leq 0.1 \\
2.35\left(0.213+\frac{1}{X_{t t}}\right) & \frac{1}{X_{t t}}>0.1
\end{array}\right. \\
& S=\frac{1}{1+0.00000253 R e_{t p}^{1.17}} \\
& \alpha_{l}=0.023 \operatorname{Re}_{l o}^{0.8} \operatorname{Pr}_{l}^{0.4}\left(\frac{k_{l}}{d_{i}}\right) \\
& \alpha_{n b}=0.00122\left(\frac{k_{l}^{0.79} c_{p, l}^{0.45} \rho_{l}^{0.49} \Delta T_{\text {sat }}^{0.24} \Delta P_{\text {sat }}^{0.75}}{\sigma^{0.5} \mu_{l}^{0.29}\left(h_{f g} \rho_{v}\right)^{0.24}}\right)
\end{aligned}
$$

Shah [25]

$$
\begin{aligned}
& \alpha_{t p}=\max \left\{\alpha_{n b}, \alpha_{c b}\right\} \\
& \alpha_{c b}=1.8 N^{-0.8} \alpha_{l} \\
& \alpha_{n b}=\left(230 \mathrm{Bo}^{0.5}\right) \alpha_{l} \text { Bo }>3 \times 10^{-4} \mathrm{~N}>1 \\
& \alpha_{n b}=\left(1+46 B o^{0.5}\right) \alpha_{l} \text { Bo } \leq 3 \times 10^{-4} N>1 \\
& \alpha_{n b}=\alpha_{l} F B o^{0.5} \exp (2.74 N-0.1) B o \leq 3 \times 10^{-4} \quad 0.1<N \leq 1 \\
& \alpha_{n b}=\alpha_{l} F B o^{0.5} \exp (2.74 N-0.15) B o \leq 3 \times 10^{-4} \quad N<0.1 \\
& N=\left\{\begin{array}{cc}
C o & F r_{l o} \geq 0.04 \\
0.38 C o F r_{l o}^{-0.3} & F r_{l o}<0.04
\end{array} \quad F=\left\{\begin{array}{cc}
14.7 & B o \geq 11 \times 10^{-4} \\
15.43 & B o<11 \times 10^{-4}
\end{array}\right.\right. \\
& \alpha_{l}=0.023 \operatorname{Re}_{l o}^{0.8} \operatorname{Pr}_{l}^{0.4}\left(\frac{k_{l}}{d_{i}}\right)
\end{aligned}
$$

Kandlikar [26]

$$
\alpha_{t p}=\max \left\{\alpha_{n b}, \alpha_{c b}\right\}
$$

$$
\begin{gathered}
\alpha_{n b}=\left(0.6683 \mathrm{Co}^{-0.2} \mathrm{FFr}_{l o}+1058.0 B o^{0.7} F_{f, l}\right)(1-x)^{0.8} \alpha_{l o} \\
\alpha_{c b}=\left(1.136 \mathrm{Co}^{-0.9} \mathrm{Fr}_{l o}+667.2 B o^{0.7} F_{f, l}\right)(1-x)^{0.8} \alpha_{l o}
\end{gathered}
$$




$$
\begin{gathered}
\alpha_{l o}=\frac{(f / 2)\left(R e_{l o}-1000\right) P r}{1+12.7(f / 2)^{1 / 2}\left(P^{2 / 3}-1\right)}\left(\frac{k_{l}}{d_{i}}\right) 1 \times 10^{4} \leq R e_{l o} \leq 5 \times 10^{6} \\
\alpha_{l o}=\frac{(f / 2) R e_{l o} P r}{1+12.7(f / 2)^{1 / 2}\left(P^{2 / 3}-1\right)}\left(\frac{k_{l}}{d_{i}}\right) 1600 \leq R e_{l o} \leq 1 \times 10^{4} \\
\alpha_{l o}=3.66\left(\frac{k_{l}}{d_{i}}\right) R e_{l o} \leq 1600
\end{gathered}
$$

Gungor and

$$
\alpha_{t p}=F F_{2} \alpha_{l}+S S_{2} \alpha_{n b}
$$

Winterton [27]

$$
\begin{gathered}
S=\frac{1}{1+0.00000253 \operatorname{Re}_{t p}^{1.17}} S_{2}=\left\{\begin{array}{cc}
1 & F r_{l o} \geq 0.05 \\
F r_{l o}^{\left(0.1-2 F r_{l o}\right)} & F r_{l o}<0.05
\end{array}\right. \\
F=1+24000 B o^{1.16}+1.23\left(\frac{1}{X_{t t}}\right)^{0.86} F_{2}=\left\{\begin{array}{cc}
1 & F r_{l o} \geq 0.05 \\
F r_{l o}^{0.5} & F r_{l o}<0.05
\end{array}\right. \\
\alpha_{n b}=55 P_{r}^{0.12}\left(-\log _{10} P_{r}\right)^{-0.55} M^{-0.5} q^{0.67} \\
\alpha_{l}=0.023 \operatorname{Re}_{l o}^{0.8} \operatorname{Pr}_{l}^{0.4}\left(\frac{k_{l}}{d_{i}}\right)
\end{gathered}
$$

Liu and

$$
\alpha_{t p}=\left(\left(F \alpha_{l}\right)^{2}+\left(S \alpha_{n b}\right)^{2}\right)^{0.5}
$$

Winterton [28]

$$
\begin{gathered}
F=0.35\left[1+x P r_{l}\left(\frac{\rho_{l}}{\rho_{v}}-1\right)\right] \\
S=\frac{1}{1+0.055 F^{0.1} \operatorname{Re}_{t p}^{1.16}} \\
\alpha_{l}=0.023 \operatorname{Re}_{l o}^{0.8} P r_{l}^{0.4}\left(\frac{k_{l}}{d_{i}}\right) \\
\alpha_{n b}=55 P_{r}^{0.12}\left(-\log _{10} P_{r}\right)^{-0.55} M^{-0.5} q^{0.67}
\end{gathered}
$$

Panek [29]

$$
\begin{gathered}
\alpha_{t p}=3.683 \alpha_{l} X_{t t}^{-0.563} \\
\alpha_{l}=0.023 R e_{l o}^{0.8} \operatorname{Pr}_{l}^{0.4}\left(\frac{k_{l}}{d_{i}}\right)
\end{gathered}
$$


Table 6. Summary of the comparison between the calculated and experimental results.

\begin{tabular}{|c|c|c|c|c|c|}
\hline Correlation & - & $\mid$ & $\max$ & & $10 \%$ \\
\hline \multicolumn{6}{|c|}{ Evaporating pressure } \\
\hline Chen [24] & $10.04 \%$ & $10.04 \%$ & $29.21 \%$ & $5.41 \%$ & $57.58 \%$ \\
\hline Shah [25] & $-6.74 \%$ & $7.11 \%$ & $-18.07 \%$ & $4.30 \%$ & $75.76 \%$ \\
\hline Kandlikar [26] & $-3.18 \%$ & $4.87 \%$ & $-15.15 \%$ & $4.92 \%$ & $93.94 \%$ \\
\hline Gungor and Winterton [27] & $-6.60 \%$ & $7.07 \%$ & $-17.72 \%$ & $4.61 \%$ & $77.78 \%$ \\
\hline Liu and Winterton [28] & $5.87 \%$ & $6.05 \%$ & $23.62 \%$ & $4.95 \%$ & $85.86 \%$ \\
\hline Panek [29] & $-7.46 \%$ & $7.50 \%$ & $-13.09 \%$ & $2.61 \%$ & $86.87 \%$ \\
\hline \multicolumn{6}{|c|}{ Refrigerant temperature at the evaporator outlet } \\
\hline Chen [24] & $1.10 \%$ & $1.10 \%$ & $2.80 \%$ & $0.50 \%$ & $100 \%$ \\
\hline Shah [25] & $-0.57 \%$ & $0.64 \%$ & $-1.84 \%$ & $0.48 \%$ & $100 \%$ \\
\hline Kandlikar [26] & $-0.20 \%$ & $0.45 \%$ & $-1.52 \%$ & $0.53 \%$ & $100 \%$ \\
\hline Gungor and Winterton [27] & $-0.55 \%$ & $0.64 \%$ & $-1.80 \%$ & $0.51 \%$ & $100 \%$ \\
\hline Liu and Winterton [28] & $0.70 \%$ & $0.71 \%$ & $2.32 \%$ & $0.49 \%$ & $100 \%$ \\
\hline Panek [29] & $-0.65 \%$ & $0.66 \%$ & $-1.17 \%$ & $0.28 \%$ & $100 \%$ \\
\hline \multicolumn{6}{|c|}{ Brine temperature at the evaporator outlet } \\
\hline Chen [24] & $-0.06 \%$ & $0.06 \%$ & $-0.17 \%$ & $0.04 \%$ & $100 \%$ \\
\hline Shah [25] & $-0.01 \%$ & $0.03 \%$ & $-0.12 \%$ & $0.04 \%$ & $100 \%$ \\
\hline Kandlikar [26] & $-0.02 \%$ & $0.03 \%$ & $-0.12 \%$ & $0.04 \%$ & $100 \%$ \\
\hline Gungor and Winterton [27] & $-0.01 \%$ & $0.03 \%$ & $-0.12 \%$ & $0.04 \%$ & $100 \%$ \\
\hline Liu and Winterton [28] & $-0.05 \%$ & $0.05 \%$ & $-0.16 \%$ & $0.04 \%$ & $100 \%$ \\
\hline Panek [29] & $-0.01 \%$ & $0.03 \%$ & $-0.10 \%$ & $0.03 \%$ & $100 \%$ \\
\hline
\end{tabular}

